\title{
Content Management Implemented as Shared Service: A Public Sector Case Study
}

\author{
Anton Joha ${ }^{1}$ and Marijn Janssen ${ }^{2}$ \\ ${ }^{1}$ EquaTerra, 150 Minories, London, EC3N 1LS, United Kingdom, \\ Tel.: +44 (0)8458387500 \\ anton.joha@equaterra.com \\ ${ }^{2}$ Delft University of Technology, Faculty of Technology, Policy \& Management \\ Jaffalaan 5, 2600 GA Delft, The Netherlands \\ Tel.: +31 (0)15 2781140 \\ m.f.w.h.a.janssen@tudelft.nl
}

\begin{abstract}
Sharing services has gained the interest of governments to reduce costs. The basic idea is that services provided by one department can be provided to others with relatively few efforts. A new emerging trend is the implementation of content management (CM) shared services. As a new phenomenon, there is little understanding of this concept. This paper addresses this knowledge gap by investigating a public sector case study and analyzing the decision process concerning the introduction of a CM for Shared Service Centers (SSCs). The case is analyzed using a decision framework based on a multi-theory approach found in outsourcing literature. The differences with other types of SSCs are highlighted. The complexity of this arrangement originates from the need to manage content in the many parts of the organization and the involvement of many different roles. A CM SSC requires a holistic decision-making approach by balancing the management, technology and content dimensions carefully, as these dimensions influence the resulting arrangement and potential benefits.
\end{abstract}

Keywords: Content Management, Public Sector, Shared Services, Sourcing.

\section{Introduction}

There has been an explosion of information created and used by governments internally, but also provided by governments via the Internet to inform or facilitate citizens. As such, governments are looking for ways to manage the myriad of content in an efficient and effective manner. In a report, Doculabs identifies the use of shared services for content management as a new frontier for governments to reduce costs, and improve quality, alignment, compliance and control [1]. Shared services have been hailed as a solution to reduce costs and improve services, although the promises might be relatively difficult to realize [e.g. 2]. By unbundling services and then concentrating them within a shared services center, the basic premise for shared services is that services provided by one department or organization can be provided to others with relatively few efforts [e.g. 2, 3, 4]. This should result in both cost 
savings and service quality improvements. The choice for sharing services is a major decision that has a long-term and strategic impact [2]. Governments are under increasing pressure to be transparent by sharing and making their information publicly available [5, 6]. New technological advances allow organizations with data-intensive processes and ever increasing amounts of content like reports, forms, e-mails, spreadsheets, images and other digital content that is used for internal or external purposes, to deliver content management functionality as a shared service. This approach should result in economies of scale and scope by centralizing and standardizing the content on the one hand, and in the effective creation and use of decentralized content by its users on the other hand $[7,8]$.

In this paper, we use a decision framework to explore a content management (CM) SSC. The aim of this paper is to identify and understand the decision choices that need to be made when introducing and implementing such a novel shared services arrangement. The research described in the paper has an explorative-descriptive nature and a retrospective view of the decision process of the introduction of a SSC was created. The structure of the paper is as follows. In the following section, we discuss the theoretical background and the decision framework for analyzing the CM SSC case study. This is followed by a section with an outline of the research approach used to gather and analyze the data. The following section then describes the case study of a shared service arrangement in the Commonwealth of Virginia in detail, while in the next section the empirical findings are further analyzed and discussed. In the final section, the key research findings are highlighted and conclusions are drawn.

\section{Background}

\subsection{Content Management}

Content management is the set of processes and technologies that support the collection, managing, and publishing of information in any form or medium. Much of the content is stored in information silos and not serving the user base of the whole organization [1]. Goodwin and Vidgen [9] view content management as a process instead of a product and define it as "an organizational process, aided by software tools, for the management of heterogeneous content on the web, encompassing a life cycle that runs from creation to destruction". Content management is a collaborative process. Different roles are involved in this process, e.g. the creator of the content, the editor and quality manager, the administrator and the user who wants to read or use the content [10-12]. Goodwin and Vidgen [9] describe the content life-cycle by the main processes of create, review, store, publish/exchange, archive and destroy. They found that despite all efforts CM is a difficult endeavor and challenges include content revision, consistency, navigation, data duplication, content audit and control, track, authorize and reconstruct changes.

\subsection{Shared Services}

SSCs are a particular type of sourcing arrangement, where resources and services are retained in-house. There are many definitions of SSCs in literature [13]. Generally, a SSC is a separate and accountable semi-autonomous unit within an (inter) organizational 
entity, used to bundle activities and provide specific pre-defined services to the operational units within that (inter)organizational entity, on the basis of agreed conditions [3]. SSCs seem to be especially suitable for public administrations, as in current practice each agency often develops and maintains its own systems and services [14, 15]. By bundling the development, maintenance and use of services, the costs can be shared among the agencies, innovations out of reach might become feasible, and the money freed can be used to improve service levels without any of the agencies having to give up their autonomy.

\subsection{Decision Framework}

There are many theories underpinning sourcing theory and its decision-making process. Lee et al. [16] and Jayatilaka, Schwarz, and Hirschheim [17] provide an overview of sourcing theories and the strategic determinants influencing these decisions. We adopt a process-driven, multi-theory decision approach and use four major decision categories for implementing shared services: (a) make-or-buy decision, (b) scope and type of shared-service arrangement, (c) cost benefits and risks assessment, and (d) implementation choice and change management strategy. This framework was used in previous research to analyze SSCs in other areas [18]. The categories are shown in the left column of Table 1. In general, the process starts when politicians and/or public managers make the sourcing decision. Next, the scope and type of the shared-service arrangement should be decided on, which will result in the identification of various options available to share services. Thereafter, the cost benefits and risks of the identified options should be assessed and the decision to implement one arrangement should be taken. Finally, the shared-service arrangement should be implemented using a change management strategy.

Table 1. Decision categories when introducing SSCs and their driving theories and motto (based on [16])

\begin{tabular}{|l|l|l|}
\hline $\begin{array}{l}\text { Decision } \\
\text { categories }\end{array}$ & Driving theories & Driving motto \\
\hline $\begin{array}{l}\text { 1. Make-or-buy } \\
\text { decision }\end{array}$ & $\begin{array}{l}\text { - Core competencies theory } \\
\text { - Resource-based theory }\end{array}$ & $\begin{array}{l}\text { Performing activities either in- } \\
\text { house or by external suppliers. }\end{array}$ \\
\hline $\begin{array}{l}\text { 2. Scope and type } \\
\text { of shared services } \\
\text { arrangement }\end{array}$ & $\begin{array}{l}\text { - Coordination theory } \\
- \text { Resource dependency theory } \\
- \text { Transaction cost theory }\end{array}$ & $\begin{array}{l}\text { Determining the potential scope } \\
\text { and options for sharing services, } \\
\text { including the objectives that should } \\
\text { be met. }\end{array}$ \\
\hline $\begin{array}{l}\text { 3. Cost benefits } \\
\text { and risks } \\
\text { assessment }\end{array}$ & $\begin{array}{l}\text { - Power-political theory } \\
- \text { Principal-agent theory } \\
\text { - Transaction cost theory }\end{array}$ & $\begin{array}{l}\text { Assessing the financial feasibility } \\
\text { of the shared services options, also } \\
\text { taking into account the risks } \\
\text { involved. }\end{array}$ \\
\hline $\begin{array}{l}\text { 4. Implementation } \\
\text { choice and change } \\
\text { management } \\
\text { strategy }\end{array}$ & $\begin{array}{l}\text { - Power-political theory } \\
- \text { Organizational theories }\end{array}$ & $\begin{array}{l}\text { Defining the optimal way to } \\
\text { implement the shared services } \\
\text { concept within the organization. }\end{array}$ \\
\hline
\end{tabular}


The make-or-buy decision for sourcing is largely explained by resource-based theory and core competency theory, which state that organizations should retain core capabilities in-house and that non-core capabilities do not have to be owned. Choices about the scope of services and the type of shared-service arrangement are driven by coordination, transaction costs, and resource dependency theory. Coordination theory looks at the management of interdependencies between organizational business processes [19]. The basic idea behind resource dependency theory is that organizations are dependent on external resources to function [20]. The problem that resource dependency theory emphasizes is that the environment changes and resources become more or less scarce, resulting in power differences between organizations and providing an explanation of how independent organizations come to depend on and dominate each other. Cost benefits and risks assessment of the selected sourcing options are often based on the power-political, principal-agent, and transaction cost theories. The basic idea of outsourcing is based on the transaction cost theory [21]. Transaction costs result from the transfer of property rights between parties and exist because of friction in economic systems. The idea is that an organization will tend to expand until the cost of organizing an extra transaction internally becomes equal to or higher than the costs of carrying out the same transaction on the open market. The use of a communication network and integration technology will decrease the transaction costs, enabling organizations to source functions and to focus on their core competencies. Finally, principal-agent theory deals with the relationship between the principal and agent based on the division of labor, information asymmetry and environment, and partner behavior [22]. Both the transaction cost and principal-agent theories are based on rationality, an efficiency criterion used for explaining outsourcing structures. Political organizational theories are used for explaining organizational arrangements and include social, coordination, risk, and strategic management theories. These view actors as political entities having different degrees of power. The way shared services will be implemented and how changes are managed depend on power political and organizational theories, which are interdisciplinary and based on knowledge from the fields of psychology, political science, economics, anthropology, and sociology. They seek to explain behavior and dynamics in both individual and group contexts.

\section{Research Methodology}

The objective of this study is to analyze and improve our understanding of a content management SSC in practice by identifying the issues involved during the decisionmaking phase. This analysis should increase our knowledge of a CM SSC and can be used by practitioners to support the change process. Theory concerning a Content Management SSC is scarce and owing to the complex nature of shared service arrangements, a qualitative approach based on a case study research was adopted for this research [23]. In the shared services both technology and organizational issues play a role. Case study research is one of the most common qualitative method used in information systems (IS) [24]. The case study research methodology is particularly well-suited to IS research, since the object of the discipline is the study of IS in organizations, and the "interest is shifted to organizational rather than technical 
issues" [25]. This research was based primarily on secondary data collection and evaluation in a qualitative setting. Documents, presentations, internal reports relating to the set up of a SSC were gathered and examined in order to acquire a good understanding of the decision-making processes and aspects. The analysis of documents allowed creating a retrospective view of the decision processes that contribute to the understanding of content management shared service arrangements.

\section{Case Study}

The Commonwealth of Virginia is a U.S. state on the Atlantic Coast of the Southern United States which is well known for its innovative capacity. The capital of the Commonwealth is Richmond and the state population is nearly eight million [26]. The modern government is ranked by the Pew Center on the States with an A- in terms of its efficiency, effectiveness, and infrastructure. This is the second time Virginia received the highest grade in the nation, which it shares with two others [27]. The Content Management (CM) initiative is focused on promoting the adoption of CM throughout the Commonwealth. Prior to a Commonwealth-wide focus on CM, several agencies had implemented their own agency-specific CM systems based on a variety of platform solutions. In 2008, a feasibility study was done to create a shared service offering and based on the results of this study, it was determined that demand did exist for a CM shared service [28]. To allow agencies and localities to benefit from content management in a cost effective manner, a working group comprising representatives from 12 agencies and localities collaboratively designed a content management shared services offering that would have to be operational at the end of 2009. The CM Shared Service is realized by a single solution platform that is utilized by multiple agencies and localities. Agency content is stored in a consolidated CM repository with appropriate security to control retrieval access. Each participating agency or locality shares in the use and corresponding costs of the hardware, software, and support resources that comprise the offering and agencies pay on a per user basis for use of the service.

While agencies will still be responsible for their mission-specific applications, an increasingly greater number of application functions can be provided and maintained centrally [29]. Shared services can improve service delivery and potentially free agency resources. This goes beyond the area of CM and touches other areas. In combination with other areas improved economies of scope and scale might be accomplished [29].

\subsection{Make-or-Buy Decision}

Content management is primarily an internal core function, where internal, confidential documents are shared between employees and external documents are shared with citizens. The question whether to outsource this function or to keep it inhouse was not an issue as CM was viewed as a core function because of its direct impact on daily operations and risk regulation requirements. This follows the suggestion by resource-based and core competency theory. An important issue at this stage is to determine which CM activities such as the implementation and testing, can 
be outsourced and if the organization is already using certain third parties that deliver the technology and software to support content management, in order to be sure that the future solution is consistent and compatible with the already existing technology.

\subsection{Scope and Type of Shared-Service Arrangement}

The goals for introducing the CM shared services offering are [30]:

- Cost reduction and operational efficiencies by more customer-oriented business processes, reduce manual inputting, faster and easier information finding, more efficient use of resources, eliminate having redundant copies of documents and reduce the volume of paper resulting in less physical storage requirements and costs related to space, printing, copying, filing and distribution.

- Resolve retention issues by having a searchable document repository, and appropriate destruction of documents reduces the cost and time required to respond to the Freedom of Information Act (FOIA), eDiscovery and audit requests, automated linkage to records management retention policies allows appropriate retention and destruction of documents, automated approval routings and document holds prevent improper destruction of documents.

- Increased security and risk reduction by having a secure repository ensuring confidentiality of information, facilitating disaster recovery options, supporting accountability and agile decision-making, increasing compliance with legislation, regulation and potential litigation.

- Customer improvement by providing customer-centric services to citizens, businesses, and government entities making the services easier to use, more accessible, more cost efficient and by managing enterprise information by making all appropriate state-managed data available to all levels of government, citizens and businesses.

The above shows that the goal was to realize a variety of objectives in different areas. The CM Shared Service was intended to provide the following core functions:

- "Scan Interface: The ability to accept scanned documents and metadata from industry standard scanning and document capture software to index and provide long-term storage in the content repository.

- Store: The ability to accept, index, and provide long-term storage of content.

- Search: The ability to perform content searches based on a set of stored metadata and full-text search.

- Retrieve: The ability to view selected content, typically as a result of a performed search.

- Records Management: The application of Library of Virginia-approved retention and disposition schedules to facilitate appropriate retention and timely destruction of records protected by the Code of Virginia.

- Basic Security: The use of security provisions to require appropriate authentication and authorization to search, retrieve, view, add, and modify content.

- Email Management (Manual): The ability to manually capture, index, and store emails (e.g. drag \& drop to folder in Outlook) into the content repository. 
- Simple Workflows: The use of simple workflow capabilities including acceptance of scanned image content and simple linear step processes (e.g., three-step approval workflow)." [31]

Following Malone [32], coordination is defined as "the additional information processing performed when multiple, connected actors pursue goals that a single actor pursuing the same goals would not perform". This both affects which services can be shared as well as the way these services need to be shared in terms of its governance. There are 4 organizational entities and roles involved in the Commonwealth's CM SSC governance [28]:

- The CM SSC is responsible for the provision of CM services. There is a core staff with ECM architect, system administrator, business analyst, and project manager roles who have to ensure a good performance of the CM system, and also are involved in program management for those agencies that also want to use the CM platform. Internal users can get support or training regarding the $\mathrm{CM}$ system via the CM SSC.

- The Chief Applications Officer (CAO) and the office of the CAO, responsible for demand governance in terms of setting business strategy and application standards.

- The Chief Information Officer (CIO) and the office of the CIO, responsible for supply governance in terms of setting the IT strategy, policy and delivering the technology underlying the business services.

- The internal and external users using the CM SSC by creating content as input for the $\mathrm{CM}$ system and using its documents.

The CAO is ultimately responsible for the CM SSC and the program management required to extending the scope of the $\mathrm{CM}$ shared service to other agencies, but strategic and tactical decisions that have to be made regarding the CM SSC will be discussed in a board with representatives from the offices of the CAO, CIO and the internal user organization.

\subsection{Cost Benefits and Risks Assessment}

Before Commonwealth started to introduce the CM SSC offering, they assessed the potential cost savings. Commonwealth had to sort through and determine in which activities sharing was possible (see 4.2), where their mission-specific and data privacy boundaries lay, and what they hold in common. This data was used to calculate the cost savings that could be achieved by sharing services. Also the costs for software, hardware, storage, licenses and supporting staff had to be determined. In this analysis the alternative without SSC was also calculated by determining the total recoveries. In table 2, the business case is presented that was created for implementing the CM SSC.

Table 3 shows what investments need to be made for implementing the CM SSC over the coming 5 years, where the number of users is assumed to increase each year. The total investment costs can be compared with the costs that can be saved. The breakeven point occurs between month 42 and 45 [33]. It should be noted that realizing cost reduction is often more complicated than initially thought [2]. Central 
procurement is possible for licenses, software, hardware, etc, and therefore an appropriate procurement process needs to be put in place. This refers to the principles of the transaction cost theory [21]. A governmental agency will tend to organize its own transactions until the cost of organizing an extra transaction internally becomes equal to or higher than the costs of carrying out the same transaction by or with other governmental agencies. In case an agency would implement a content management operation themselves they would need to have minimally 4 servers. Suppose that 7 agencies would do this, 28 servers would be required for each individual agency. By sharing services for these 7 agencies, and bundling the activities, 12 servers are necessary for production and 4 for delivery and testing, which adds up to only 16 servers. The content management shared services would require 5 core staff members, while each agency would need to have on average 1.5 core staff members, which would be 10.5 in total, twice as much as the content management SSC [34]. Participating agencies pay for use of the service through a flat monthly per user fee. This price is estimated to be $\$ 55$ per user per month, but the price can be subject to change as the overall cost of the offering and number of participants is refined.

Table 2. Business case for the CM Shared Service Center [33]

\begin{tabular}{|c|c|c|c|c|c|c|}
\hline & Year 1 & Year 2 & Year 3 & Year 4 & Year 5 & TOTAL \\
\hline Software & $916 \mathrm{~K}$ & $668 \mathrm{~K}$ & $\begin{array}{l}221 \mathrm{~K}- \\
632 \mathrm{~K}\end{array}$ & $\begin{array}{l}632 \mathrm{~K}- \\
1.11 \mathrm{M}\end{array}$ & $\begin{array}{l}700 \mathrm{~K}- \\
1.25 \mathrm{~K}\end{array}$ & $\begin{array}{l}3.14 \mathrm{M}- \\
4.58 \mathrm{M}\end{array}$ \\
\hline Hardware & $565 \mathrm{~K}$ & $569 \mathrm{~K}$ & $\begin{array}{l}622 \mathrm{~K}- \\
726 \mathrm{~K}\end{array}$ & $\begin{array}{l}726 \mathrm{~K}- \\
934 \mathrm{~K}\end{array}$ & $\begin{array}{l}830 \mathrm{~K}- \\
1.14 \mathrm{M}\end{array}$ & $\begin{array}{l}3.21 \mathrm{M}- \\
3.83 \mathrm{M}\end{array}$ \\
\hline $\begin{array}{l}\text { Support } \\
\text { Resources }\end{array}$ & $302 \mathrm{~K}$ & $556 \mathrm{~K}$ & $605 \mathrm{~K}$ & $605 \mathrm{~K}$ & $\begin{array}{l}605 \mathrm{~K}- \\
970 \mathrm{~K}\end{array}$ & $\begin{array}{l}2.67 \mathrm{M}- \\
3.04 \mathrm{M}\end{array}$ \\
\hline Implementation & $\begin{array}{l}250 \mathrm{~K}- \\
500 \mathrm{~K}\end{array}$ & 0 & 0 & 0 & 0 & $\begin{array}{l}250 \mathrm{~K}- \\
500 \mathrm{~K}\end{array}$ \\
\hline Total Costs & $\begin{array}{l}1.93 \mathrm{M}- \\
2.18 \mathrm{M}\end{array}$ & $1.79 \mathrm{M}$ & $\begin{array}{l}1.45 \mathrm{M}- \\
1.96 \mathrm{M}\end{array}$ & $\begin{array}{l}1.96 \mathrm{M}- \\
2.65 \mathrm{M}\end{array}$ & $\begin{array}{l}2.14 \mathrm{M}- \\
3.36 \mathrm{M}\end{array}$ & $\begin{array}{l}9.27 \mathrm{M}- \\
11.95 \mathrm{M}\end{array}$ \\
\hline Total Recoveries & $\begin{array}{l}884 \mathrm{~K}- \\
922 \mathrm{~K}\end{array}$ & $\begin{array}{l}1.77 \mathrm{M}- \\
1.84 \mathrm{M}\end{array}$ & $\begin{array}{l}2.12 \mathrm{M}- \\
2.95 \mathrm{M}\end{array}$ & $\begin{array}{l}2.83 \mathrm{M}- \\
4.42 \mathrm{M}\end{array}$ & $\begin{array}{l}3.54 \mathrm{M}- \\
5.9 \mathrm{M}\end{array}$ & $\begin{array}{l}11.14 \mathrm{M}- \\
16.03 \mathrm{M}\end{array}$ \\
\hline Number of Users & $\begin{array}{l}1.000- \\
1.500\end{array}$ & $\begin{array}{l}2.000- \\
3.000\end{array}$ & $\begin{array}{l}3.000- \\
4.000\end{array}$ & $\begin{array}{l}4.000- \\
6.000\end{array}$ & $\begin{array}{l}5.000- \\
8.000\end{array}$ & \\
\hline
\end{tabular}

\subsection{Implementation Choice and Change Management Strategy}

A change readiness assessment was designed to determine the organization's capability of, and receptivity toward, a planned change [35]. Such an assessment was conducted and the results of the assessments formed a baseline and may be readministered to measure change over time. Moreover, the results were used to inform the change management strategy and plan and to help reduce project risks. The introduction of a CM SSC was perceived by the respondents as positive [35]. They came up with various suggestions including:

- Use the data to shape change management and PMO activities

- Continue involvement of agencies in system design 
- $\quad$ Engage agencies in developing implementation strategies

- Provide post-implementation training for management on "how" to use the system information to manage better

- Actively pursue funding and leadership engagement

Another outcome was that the more personal the impact of the implementation, the more personal the communication method desired [35]. Organizational theories pay attention to how a change strategy needs to be implemented. Three main strategies exist, the big-bang strategy, an incremental strategy, or a combination of these two strategies [36]. Commonwealth used the incremental strategy by first doing a pilot and then gradually trying to connect as many agencies as possible to use the shared service. However, the technology and platform to support all potential agencies was already anticipated for and implemented.

\section{Discussion}

A sound and unified decision structure will give everyone a voice in the functionality and services provided by the CM SSC. Bramscher \& Butler [37] identify three different roles that are critical to the success of a content management system as a technology that enables an organization to meet the needs of its users. They identify the content role, responsible for pushing out digital material or objects by nontechnical staff, the management role responsible for facilitating decisions regarding the architecture and distribution of authorship and editorial roles, and the technology role responsible for providing the technological platform and mechanisms to carry this out enables an organization to meet the needs of its users [37]. We have used their framework to map these roles on the different stakeholders involved in the Commonwealth's decision process in order to show where the different responsibilities are located, as shown in figure 1.

The management role is associated with coordination theory as it's mainly concerned with the management of interdependencies between organizational business processes, while the technology role is mainly associated with transaction cost theory because of its responsibility for communication network and integration technology that will decrease the transaction costs and its potential to outsource certain technological activities in case a third party can provide these more costefficiently. The content role is mainly linked to resource-based theory and core competency theory because the users provide the specific knowledge that is core to the organization. The relationship between these three roles can be analyzed from the principal-agent theory perspective.

The case study suggests that there needs to be a good balance between the above roles during the decision process to align the business requirements with the available technology in such a way that users are able to make use of the content management system in the most efficient and effective way. This requires a holistic decision making approach. 


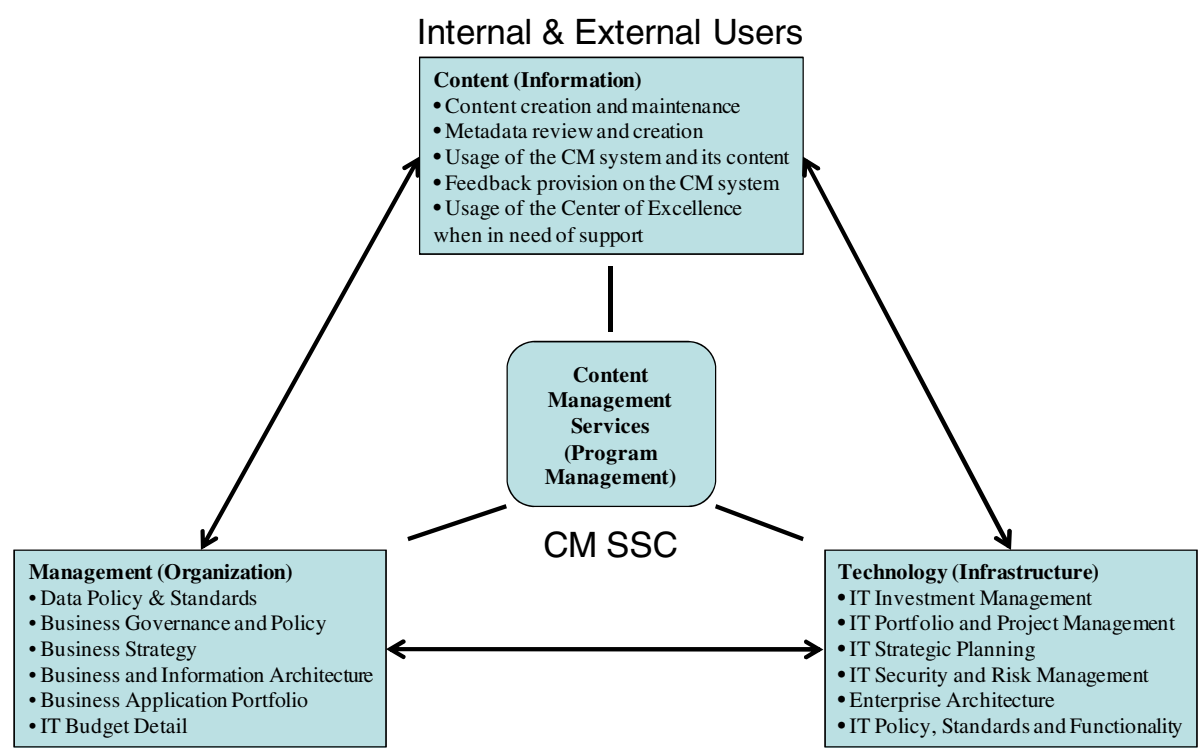

Office of the CAO

Office of the $\mathrm{ClO}$

Fig. 1. Virginia's decision structure, roles and responsibilities [based on 37]

\subsection{Differences between a CM SSC and SSCs in Other Areas}

The case study shows that the implementation of a content management shared service center differs from shared services implementations in other areas [see for example 2, 3, 38] in several ways. These differences are related to the nature of the respective arrangements.

First, in other SSCs, activities and systems are bundled that are generally only relevant for and apply to one or more specific parts of the organization. In case of a CM SSC, activities and systems are bundled that are relevant for and apply to the whole organization. This will influence the way the applications, data and technical architecture of the underlying $\mathrm{CM}$ platform will have to be structured and this organization and technology dimension.

Second, SSCs in other field provide services to the internal organization and in some instances also to external customers. In general only the SSC employees do have access to the systems they are working with. In a CM SSC, this is different. Everyone within the organization is able to use the system and provide input and feedback. A content management solution therefore requires identity, access and security management, to deal with so many users. Moreover digital forms and signatures need to be introduced to ensure that external customers can securely use the documents and forms. This all involves the technology and content dimension. Finally, training, education and support will become more important, as all of the employees will potentially use the content management system (CMS).

Third, SSCs in other areas are often not as technically oriented as the content management SSC. Usually SSC start with the unbundling and concentration of business 
processes which are supported by technology. Whilst in CM-CSS the concentration of technology is the driver and only the supporting (helpdesk) processes are shared. Information technology pervades, affects and even shapes most organizational processes in some way [39], and this could have potential consequences for the business processes. This affects the organization, technology and content dimension. This also shows that the way governance is defined becomes more relevant as it involves coordination on all of the above mentioned dimensions.

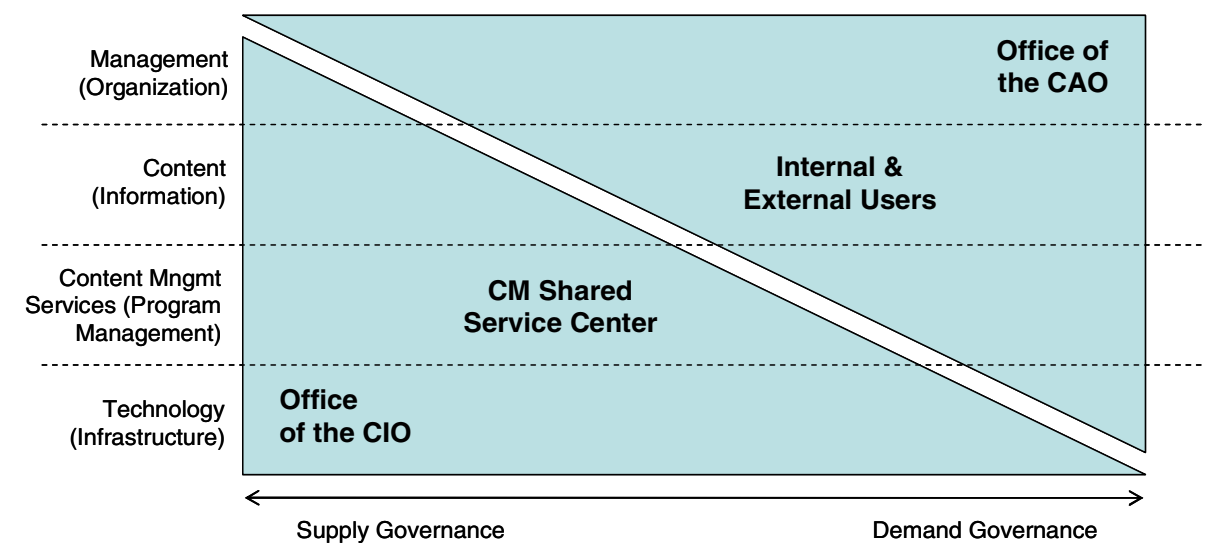

Fig. 2. Main responsibilities of the organizational entities in the CM SSC decision process

Figure 2 is an extension of figure 1, showing which organizational entities are responsible for which specific content management dimension and how the SSC relates to these entities. The CM SSC and the Office of the CIO are involved with supply governance, implying that they are providing content management and its related IT services to the internal and external users. The office of the CAO is responsible for demand governance in terms of defining the policies, standards and functionality of the CM system. Besides using the content management system and creating content that is used as input for the system, users are also supposed to provide feedback on its functionality in order to further improve the system.

\section{Conclusions}

For most governments the management of content is its core business. The availability of consistent and correct content is necessary for ensuring trust in governments. The choice for a SSC requires considerable organizational changes and should be based on a long term strategy. In this paper we explored an emerging new form of shared services, a Content Management SSC (CM SSC). CM SSCs have some peculiar aspects which makes them different from SSCs in other areas. Whereas in other areas activities and systems are bundled in a SSC that are generally only relevant for and apply to a specific part of the organization, in case of a CM SSC, activities and systems are bundled that are relevant for and apply to the whole 
organization. Most persons in the organization are involved in content management. Moreover, in other SSC arrangement generally only the SSC employees do have access to the systems they are working with, while in a CM SSC everyone within the organization is able to use the system and provide input and feedback. Another difference is that a SSC normally includes business processes and is not as technically oriented as the CM SSC. In the investigated case study no business processes are included in the SSC and the CM system itself is the central service that is shared.

To better understand the typical decision choices when implementing a CM SSC, a case study was analyzed. The peculiar characteristics of CM influence the way the CM SSC has to be implemented and highlight the decision-making issues that need to be resolved before implementation. These include decisions about the applications, data and technical architecture of the underlying CM platform, the way the governance needs to be defined, access and security management, digital forms and signatures that need to be introduced, training and support that needs to be given, and a procurement function that needs to be skilled to procure licenses, software, hardware. In this view, content management is often linked to other areas like procurement, Human Resources (HR), ePayment, Business Intelligence, and Portals. In this light, greater economies of scope and scale might be created by taking these areas also in account.

The CM SSC was introduced based on expectations about cost reduction and service improvement, but these depend on the economies of scope that can be achieved and the adoption rate, which are again dependent on factors as training, functionality, data security and governance mechanisms and infrastructure systems like digital signature. The factors relevant for the implementation affect the decisionmaking factors to introduce a CM SSC and vice versa. The design of a CM SSC business model seems to be a compromise balancing the management, technology, content and governance dimensions and as such it is of key importance that the decision making process of a CM SSC follows a structured, systematic and holistic approach, constantly using the potential feedback that is received on the various dimensions form the different stakeholders involved.

To our knowledge this is the first research analyzing the decision process concerning the introduction of a Content Management SSC and therefore we opted for investigating a case study. The case study has limited generalizability, however, the implementation strategy and issues presented in this paper can help decisionmakers to understand the various dimensions associated with the introduction of a CM SSC. For further research we suggest to investigate the factors, dimensions, benefits, disadvantages, risks, types of organizational arrangements and decisionmaking processes in more detail to get better grip on these types of arrangements.

\section{References}

1. Doculabs: ECM as a Shared Service: The new frontier (2009)

2. Janssen, M., Joha, A.: Motives for Establishing Shared Service Centers in Public Administrations. International Journal of Information Management 26, 102-116 (2006)

3. Bergeron, B.: Essentials of Shared Services. John Wiley \& Sons, Chichester (2003)

4. Accenture: Shared Services: Government Shared Services Model for High Performance (2006) 
5. Layne, K., Lee, J.: Developing fully functional E-government: A four stage model. Government Information Quarterly 18, 122-136 (2001)

6. Yang, D.-H., Kim, S., Nam, C., Lee, I.-g.: The Future of e-Government: Collaboration Across Citizen, Business, and Government. In: Traunmüller, R. (ed.) EGOV 2004. LNCS, vol. 3183, pp. 558-559. Springer, Heidelberg (2004)

7. Hodgkinson, S.L.: The Role of the Corporate IT Function in the Federal IT Organization. In: Earl, M.J. (ed.) Information Management: The Organizational Dimension, pp. 247269. Oxford University Press, Oxford (1996)

8. Bauer, B.T.: Is a Centralized or Decentralized IT Organization Better? Darwin Magazine (October 2003)

9. Goodwin, S., Vidgen, R.: Content, Content Everywhere... Time to stop and think? The process of web content management. Computing and Control Engineering Journal 13, 6670 (2002)

10. Suh, P., Addey, D., Thiemecke, D., Ellis, J.: Content Management Systems. Peer Information Inc. (2002)

11. Asprey, L., Middleton, M.: Integrative Document \& Content Management: Strategies for Exploiting Enterprise Knowledge. IGI Global (2003)

12. Boiko, B.: Content Management Bible. Wiley, Chichester (2004)

13. Singh, P.J., Craike, A.: Shared services: towards a more holistic conceptual definition. International Journal of Business Information Systems 3, 217-230 (2008)

14. Grant, G., McKnight, S., Uruthirapathy, A., Brown, A.: Designing Governance for shared service organizations in the public service. Government Information Quarterly 24, 522 538 (2007)

15. Borman, M.: Identifying Appropriate Governance Principles for Different Types of Sourcing Arrangement. In: Americas Conference on Information Systems, AMCIS 2009, Paper 553 (2009)

16. Lee, J.N., Huynh, M.Q., Kwok, R.C.W., Pi, S.M.: IT Outsourcing Evolution. Past, Present and Future. Communications of the ACM 46, 84-89 (2003)

17. Jayatilaka, B., Schwarz, A., Hirschheim, R.: Determinants of ASP choice: an Integrated Perspective. European Journal of Information Systems 12, 210-224 (2003)

18. Joha, A., Janssen, M.: The Strategic Determinants of Shared Services. In: Garson, D., Pour, M.K. (eds.) Handbook of Research on Public Information Technology. Information Science Reference, Hershey PA, USA, pp. 544-555 (2008)

19. Malone, T.W., Crowston, K.: The Interdisciplinary Study of Coordination. ACM Computing Surveys (CSUR) 26, 87-119 (1994)

20. Pfeffer, J., Salancik, G.R.: The external control of organisations. Stanford Business Classics, Stanford (2003)

21. Coase, R.H.: The Nature of the Firm. Economia 4, 386-405 (1937)

22. Jensen, M., Meckling, W.: Theory of the Firm: Managerial behavior, agency costs, and capital structure. Journal of Financial Economics 5, 305-360 (1976)

23. Yin, R.K.: Case study research: design and methods. Sage Publications, Newbury Park (1989)

24. Orlikowski, W.J., Baroudi, J.J.: Studying Information Technology in Organizations: Research Approaches and Assumptions. Information Systems Research 2, 1-28 (1991)

25. Benbasat, I., Goldstein, D.K., Mead, M.: The Case Research Strategy in Studies of Information Systems. MIS Quarterly 11, 369-386 (1987)

26. US_Census_Bureau: Virginia Profile (2008)

27. Somashekhar, S.: Government Takes Top Honors in Efficiency. The Washington Post (2008) 
28. Virginia: Report to the Information Technology Investment Board, Chairman, House Appropriations Committee, and Chairman, Senate Finance Committee in response to 20082010 Budget Bill. vol. 2009 (2008)

29. Virginia: Strategic Plan for Applications, vol. 2009 (2009)

30. Virginia: ECM Benefits Statement, vol. 2009 (2008)

31. Virginia: Enterprise Content Management Initiative, vol. 2009 (2008)

32. Malone, T.W.: What is coordination theory. National Science Foundation Coordination Theory Workshop (1988)

33. Virginia: Shared Services Example: Enterprise Content Management, vol. 2009 (2009)

34. Feldmann, P.: Virginia Enterprise Applications Program. General Government Subcommittee, vol. 2009 (2008)

35. Virginia: Change Readiness Assessment, vol. 2009 (2007)

36. Bruijn, J.A.d., Heuvelhof, E.F.t., in 't Veld, R.J.: Process Management; Why Project Management Fails in Complex Decision Making Processes. Kluwer Academic Publishers, Boston (2002)

37. Bramscher, P.F., Butler, J.T.: LibData to LibCMS: One library's evolutionary pathway to a content management system. Library Hi Tech. 24, 14-28 (2006)

38. Janssen, M., Joha, A.: Emerging shared service organizations and the service-oriented enterprise: Critical management issues. Strategic Outsourcing: An International Journal 1, 35-49 (2008)

39. Kern, T., Willcocks, L.: Exploring relationships in information technology outsourcing: the interaction approach. European Journal of Information Systems 11, 3-19 (2002) 